\title{
E A RAZÃO SE FEZ MÁQUINA E PERMANECE ENTRE NÓS
}

\author{
Bruno Pucci
}

\begin{abstract}
RESUMO
Este ensaio se propõe analisar a questão da técnica moderna, sua transformação em tecnologia na era das máquinas e sua permanência, soberana, entre nós. E quer fazê-lo tão somente a partir de dois ensaios do início dos anos quarenta do século que se foi. O primeiro, de Herbert Marcuse, Algumas implicações sociais da tecnologia moderna, 1941, e o outro, de Max Horkheimer e Theodor Adorno, O conceito de esclarecimento, final de 1942. Serão levados em consideração o contexto em que surgem os dois textos - e, para tal, me utilizarei do livro de Rolf Wiggershaus sobre a Escola de Frankfurt - e seus conteúdos, quando se referirem à temática em análise. $\mathrm{O}$ autor parte do pressuposto de que a ratio que se fez máquina, na era das tecnologias mecânicas, pela mediação do número, do cálculo, da equação, da padronização, desenvolveu ad infinitum sua potencialidade instrumental na era das tecnologias digitais, genéticas e cibernéticas de nossos dias; e que os estudos dos frankfurtianos dos anos 40 muito contribuem para se entender a onipresente e onipotente racionalização da vida do homem do século XXI.
\end{abstract}

Palavras-chave: Teoria Crítica. Técnica e tecnologia. Novas Tecnologias. Razão Instrumental. Herbert Marcuse. Max Horkheimer. Theodor Adorno.

\footnotetext{
Professor Titular do PPGE/FCH/UNIMEP, pesquisador do CNPq e da FAPESP e coordenador do Grupo de Estudos e Pesquisa "Teoria Crítica e Educação", com sedes na UNIMEP, UFSCar e UNESP-Araraquara.
} 


\begin{abstract}
This essay aims to analyze the question of modern technique, its transformation in technology in the age of the machines and its sovereign permanence among us. And it wants to do this starting from two essays in the beginning of the past forties. The first one is Marcuse's "Some social implications of modern technology", 1941, and the other essay is Max Horkheimer and Theodor Adorno's concept of Enlightenment written in 1942. The context in which those two texts appear will be taken into consideration $3 / 4$ and for this I will use Rolf Wiggershaus's book on the Frankfurt School and its concepts in connection to the thematic under analysis. The author starts this study from the presupposition that ration which became machine in the era of the mechanical technologies by the mediation of number, calculation, equation and standardization developed ab infinitum its instrumental potentialities in the era of digital, genetic and cybernetic technologies and that the Frankfurtian studies of the 40's contribute a lot to our understanding of the omnipresent and omnipotent rationalization of man in the XXI century.
\end{abstract}

Key words: Critical Theory. Technique and technology. New technologies. Instrumental ratio. Herbert Marcuse. Max Horkheimer. Theodor W. Adorno.

Horkheimer era o diretor do Institut für Sozialforschung, em Frankfurt-am-Main, desde outubro de 1930 e soube conduzi-lo com competência e firmeza em meio a crises ideológicas, políticas e econômicas dos anos 30 e 40. A ascensão do nacional-socialismo e a nomeação de Hitller como chanceler na Alemanha, em janeiro de 1933, ocasionaram o confisco do Instituto pelo Estado Livre da Prússia por "atividades hostis ao Estado", em maio de 1933. Mas desde fevereiro desse mesmo ano, Horkheimer tinha transferido para Genebra, Suíça, a sede oficial da administração da entidade, que passou então a ser denominada Societé Internationale de

Educ. e Filos., Uberlândia, v. 20, n. 39, p. 71-88, jan./jun. 2006. 
Recherches Sociales. Em 1934, na busca de maior segurança para o Instituto e para seus pesquisadores, instalou-o em Nova York, junto à Universidade de Colúmbia.

Marcuse começou a fazer parte do Instituto de Pesquisa Social em 1933, quando emigrado em Genebra. Antes, tinha sido inspirado em seus estudos por dois grandes filósofos dos anos 20, Georg Lukács e Martin Heidegger. No debate com Lukács e com as categorias marxistas, elaborou sua tese de doutorado, em 1922, sobre "O romance de arte alemão". De Heidegger tornou-se, inicialmente, discípulo e leitor, depois, seu assistente junto à Universidade de Freiburg (1928) e, posteriormente, seu crítico. Para este último Marcuse, o Sein und Zeit de Heidegger "não tratava das questões decisivas, 'integrando o momento atual e sua situação'. Marcuse foi o primeiro parceiro que Horkheimer mandou chamar de Genebra para Nova York. Ele deveria ser seu colaborador nas palestras filosóficas, a partir das quais esperava inspiração para um livro sobre a lógica dialético-materialista, projeto acalentado pelo diretor do Instituto desde o início dos anos 30"1.

Adorno - que tinha estudado música e composição em Viena com Alban Berg, do círculo Schönberg, em 1925, que se tornou doutor em Filosofia com Paul Tillich, em 1931, com a tese Die Konstruktion des Ästhetischen bei Kierkegaard, que tinha recebido influências determinantes de Siegfried Kracauer e particularmente de Walter Benjamin - apesar de já ter publicado textos seus na Zeitschrift für Sozialforschung ${ }^{2}$, não estava integrado oficial e administrativamente ao Instituto; mas aspirava ardentemente a isso, "quase como uma amante que insiste em se casar" - dizia ele, exilado na Inglaterra, em carta a Horkheimer em novembro de 1934. Este, por sua vez, queria garantir o talento de Adorno em prol de seu trabalho e do Instituto pelo preço mais baixo possível. Em carta a Friedrich Pollock, tesoureiro de Instituto, escrevia a respeito de Adorno: "Apesar de um conjunto de traços

1 WIGGERSHAUS, opus cit., p.133 e p. 177.

2 Revista do Instituto de Pesquisa Social. 
perturbadores que pertencem a sua personalidade, parece-me necessário colaborar com ele; é o único homem que pode colaborar na conclusão da lógica, além da assistência de Marcuse" ${ }^{\prime 3}$. Em fevereiro de 1938, Adorno se instala em Nova York como pesquisador do Instituto (meio período) e como pesquisador do Princepton RadioResearch Project (meio período). Na observação de Wiggershaus:

O conjunto das biografias mostra que nenhuma das pessoas que rodeavam Horkheimer era ativa politicamente, nenhuma provinha dos movimentos operários ou do marxismo, todas provinham de famílias judias cuja relação com o judaísmo era extremamente variável (...) a teoria marxista só [lhes $\mathrm{BP}]$ era sedutora porque parecia prometer soluções para problemáticas até então bloqueadas e, particularmente, porque parecia ser a única crítica radical da sociedade burguesa capitalista alienada, teoricamente ambiciosa, e que não se apartava da realidade ${ }^{4}$.

O projeto de Horkheimer de escrever um livro sobre a lógica dialético-materialista se fazia mais e mais presente em suas atividades de pesquisa. Inicialmente era Marcuse o homem que iria ajudá-lo nessa empreitada. Com a progressiva aproximação de Adorno, que explicitamente manifestara o desejo de ser parceiro único no projeto, considerou Horkheimer que sua ajuda seria imprescindível na construção de uma teoria concreta da sociedade. E, para tanto, teve peso fundamental o ensaio sobre o jazz. Horkheimer escreveu-lhe: "o estudo sobre o jazz me parece um trabalho particularmente notável. Pela análise rigorosa desse fenômeno insignificante, o senhor mostra toda a sociedade com suas contradições. Esse estudo seria um prato digno de um rei em qualquer publicação" ${ }^{\prime 5}$.

3 WIGGERSHAUS, opus cit., pp. 186-188-189

4 WIGGERSHAUS, ibidem., p.p. 135-136.

5 Carta de Horkheimer a Adorno, de 23 de outubro de 1936. In WIGGERSHAUS, opus cit., p. 194.

Educ. e Filos., Uberlândia, v. 20, n. 39, p. 71-88, jan./jun. 2006. 
Na perspectiva do projeto da dialética, Horkheimer escreveu em 1937, o artigo "Teoria tradicional e teoria crítica", que se tornaria célebre pelo título, pela construção dicotômica e por seu caráter político-ideológico no momento histórico em que foi escrito. "Teoria crítica" ou "teoria crítica da sociedade" era o novo nome dado ao materialismo histórico, em contraposição ao materialismo dialético dos partidos comunistas; por ter sido escrito no exílio, as palavras deviam ser contidas. No mesmo ano, a quatro mãos, com Marcuse, e como complementação do texto anterior, escreveram "Filosofia e Teoria Crítica". Em uma edição das Zeitschrift für Sozialforschung desse mesmo ano, foram publicados ainda dois outros artigos, "O mais novo ataque à Metafísica", de Horkheimer, e "O conceito afirmativo de cultura", de Marcuse. Os textos teriam nascido de "discussões coletivas" e foram celebrados como modelo de trabalho no Instituto. $\mathrm{O}$ artigo de Marcuse suscitou inúmeras críticas de Adorno, expressas em carta a Horkheimer ${ }^{6}$.

Os problemas decorrentes do exílio, as dificuldades financeiras e a indecisão do diretor do Instituto no final dos anos 30 criaram um sentimento de insegurança e de tensão entre os colaboradores, particularmente entre Marcuse e Adorno, que disputavam entre si a parceria com Horkheimer no projeto da dialética. Pois, na verdade, o Instituto representava não só uma instância prestadora de auxílio e proteção a esses pensadores judeus exilados dinheiro, possibilidade de publicação, recomendações, atestados e outras vantagens - mas também um refúgio para um trabalho válido no campo teórico. Quando Horkheimer criou uma nova sede do Instituto em Los Angeles, Califórnia, em 1941, o primeiro a ser convidado para se juntar a ele na costa Oeste foi Marcuse, que, por outro lado, recebeu de Pollock a desconfortável notícia de que sua renda mensal seria reduzida de 330 para 280 dólares. Marcuse tinha publicado há pouco o livro Razão e Revolução: Hegel e o advento da Teoria Social.

${ }^{6}$ WIGGERSHAUS, opus cit., pp. 247-249. 
A colaboração entre os dois, no livro sobre a dialética, ainda não iria começar, mas juntos discutiram a elaboração de dois textos complementares sobre o progresso, para o terceiro número da Studies in Philosophy and Social Science, revista que, devido à declaração de guerra e à transferência do local de edição de Paris para Nova York, tinha substituído a Zeitschrift für Sozialforschung, em 1940. Horkheimer assumiu a tarefa de escrever um artigo sobre a "razão" e Marcuse, sobre a "técnica". Os dois encontraram muitas dificuldades para escrever seus artigos, embora por razões diferentes. Marcuse se viu pressionado, por motivos financeiros, a tentar ingressar no corpo acadêmico da Columbia University, em Nova York, e nesta cidade, enquanto as tentativas se arrastavam, passou um bom tempo dormindo à noite num sofá do Instituto e trabalhando intermitentemente em seu artigo sobre a técnica, que recebeu o título de Some Social Implications of Modern Technology, publicado na revista do Instituto.

Quando Marcuse voltou definitivamente a Los Angeles, encontrou Horkheimer trabalhando com Adorno no artigo sobre a "razão". Horkheimer tinha lido o manuscrito Zur Philosophie der neuen Musik e ficara animado: "Se alguma vez na vida conheci o entusiasmo, - dizia ele em carta a Adorno - foi nessa leitura (...) Esse trabalho vai fundamentar tanto quanto possível nossos esforços comuns". A colaboração entre ambos no artigo foi tão estreita que Horkheimer pensou em publicá-lo sob o nome dos dois. Foi publicado, porém, com o nome apenas de Horkheimer, com o título The End of Reason, na revista do Instituto ${ }^{7}$.

Marcuse se integra ao trabalho sobre a dialética. Isso quem diz é Horkheimer em uma carta a Kirchheimer um outro membro do Instituto," Adorno trabalha sobre a cultura de massa, Marcuse, sobre a linguagem, e eu, sobre a noção de 'Aufklärung'. Naturalmente, as três seções estão ligadas estreitamente" ${ }^{\prime \prime}$. Marcuse, porém, foi perdendo espaço no projeto da dialética e pela usura

7 WIGGERSHAUS, opus cit., pp. 291-292; 294; 324-327.

8 Carta de Horkheimer a Kirchheimer, de agosto de 1942. In WIGGERSHAUS, opus cit., p. 327.

Educ. e Filos., Uberlândia, v. 20, n. 39, p. 71-88, jan./jun. 2006. 
financeira dos dirigentes do Instituto se viu forçado a obter proventos por outros meios. Em novembro de 1942, o Office of War Information ofereceu-lhe um cargo em Washington de 4600 dólares anuais e ele foi fortemente incentivado por Horkheimer a aceitar a oferta, tendo, para decepção sua, que interromper por um prazo indeterminado seu trabalho em Los Angeles. Assim se expressa em carta a Horkheimer:

Sei que, infelizmente, todos os argumentos 'racionais' me levam a aceitar o cargo em Washington. Mas tenho a impressão de que o Senhor subestima um pouco meu desejo de continuar o trabalho teórico que nós tínhamos começado. Apesar de eu não estar de acordo com algumas de suas idéias, nunca fiz mistério, onde quer que seja, de minha convicção de que não conheço, atualmente, outra tentativa intelectual que esteja mais perto da verdade e nenhum outro lugar onde se tenha ainda liberdade e estímulo para pensar9 ${ }^{9}$.

Em 1943, seis membros do Instituto estavam empregados em tempo parcial ou total no serviço público americano, contribuindo assim para o war effort exigido pelo governo. Apenas Horkheimer e Adorno dispunham de tempo integral para escrever o livro sobre a lógica dialética. O primeiro capítulo do livro ficou pronto no final de 1942. Em maio de 1944, no 50 aniversário de Friedrich Pollock, Horkheimer e Adorno apresentaram o manuscrito completo, com o título de Philosophische Fragmente. "Dialética do Esclarecimento" era o título inicial do primeiro ensaio do livro. A produtividade de Adorno e o fato de sua mulher trabalhar em tempo integral como secretária nos projetos sobre o anti-semitismo e sobre a dialética levaram Horkheimer a ceder aos insistentes pedidos de Adorno para aumento de salário, elevando seu pagamento para 400 dólares no começo de $1944^{10}$.

9 Carta de Marcuse a Horkheimer, de 15 de novembro de 1942, In WIGGERSHAUS, opus cit., p. 330.

${ }^{10}$ WIGGERSHAUS, opus cit., p. 355. 
Algumas implicações sociais da tecnologia moderna, de Marcuse, e O conceito de esclarecimento, de Horkheimer e Adorno - escritos, pois, o primeiro em 1941 e o segundo em 1942, após "discussões coletivas" notadamente entre Marcuse e Horkheimer - abordam diretamente o problema da técnica, mas a partir de enfoques diferentes. Para Marcuse, a "técnica por si" tanto pode promover o autoritarismo como a liberdade, a escassez como a abundância, o aumento do trabalho árduo como sua abolição; ela não passa de um "fator parcial". Quando, porém, integrada a um sistema e a grupos sociais que direcionam sua aplicação, ela ganha outras dimensões. Assim, ilustra Marcuse, "o nacional-socialismo é um exemplo marcante dos modos pelos quais uma economia altamente racionalizada e mecanizada, com a máxima eficiência na produção, também pode operar no interesse da opressão totalitária e da escassez continuada" ${ }^{11}$. Não eram o progresso tecnológico e a racionalização do mundo que preocupavam Marcuse e sim a forma especial pela qual o processo tecnológico estava organizado.

Para o Horkheimer e o Adorno de "conceito de esclarecimento", a técnica, desde as origens da ciência moderna, foi desenvolvida como resultado de um saber prático, vinculado ao poder e à dominação:

O saber que é poder não conhece nenhuma barreira (...) está a serviço de todos os fins da economia burguesa na fábrica e no campo de batalha (...) A técnica é a essência desse saber (...) o que os homens querem aprender com a natureza é como empregá-la para dominar completamente a ela e aos homens. Nada mais importa. (...) O que importa é a operation, o procedimento eficaz ${ }^{12}$.

Aliás, os dois autores vão ainda mais além: mostram que, até nos mitos, o saber é poder e técnica de dominação:

\footnotetext{
${ }^{11}$ MARCUSE, opus cit., pp. 73-74.

${ }^{12}$ HORKHEIMER e ADORNO, opus cit., p. 20
} 
$\mathrm{O}$ mito queria relatar, denominar, dizer a origem, mas também expor, fixar, explicar. (...) muito cedo (os mitos, BP) deixaram de ser um relato, para se tornarem uma doutrina. (...) Os mitos, como os encontraram os poetas trágicos, já se encontram sob o signo daquela disciplina e poder que Bacon enaltece como o objetivo a alcançar ${ }^{13}$.

Marcuse reserva a categoria "tecnologia" para nomear o sistema abrangente e totalitário que a técnica assumiu a partir de um determinado momento do capitalismo contemporâneo e a descreve como "a totalidade dos instrumentos, dispositivos e invenções que caracterizam a era da máquina". Para ele, a tecnologia é, ao mesmo tempo: 1. "uma forma de organizar e perpetuar (ou modificar) as relações sociais"; 2 . "uma manifestação do pensamento e dos padrões de comportamento dominantes"; 3 . "um instrumento de controle e de dominação" ${ }^{14}$. E, no desenvolvimento de seu texto, utiliza com freqüência a expressão "razão tecnológica", que, em contraposição à racionalidade individualista gerada no capitalismo liberal, leva os indivíduos, para sobreviverem, a aceitar e introjetar os ditames das máquinas: "Os indivíduos são despidos de sua individualidade, não pela coerção externa, mas pela própria racionalidade sob a qual vivem"15.

Horkheimer e Adorno não utilizam no texto daquele seu ensaio as categorias "tecnologia" e "razão tecnológica" e, neste ensaio, nem mesmo "razão instrumental". Para eles, a ratio, em seu percurso do mito à ciência moderna, se fez instrumento: "O procedimento matemático tornou-se, por assim dizer, o ritual do pensamento. (...) ele transforma o pensamento em coisa, em instrumento, como ele próprio o denomina" ${ }^{16}$; a ratio se fez sistema:

${ }^{13}$ HORKHEIMER e ADORNO, ibidem., p. 23.

${ }^{14}$ MARCUSE, opus cit., p. 73.

${ }^{15}$ MARCUSE, ibidem., p. 82.

${ }^{16}$ HORKHEIMER e ADORNO, ibidem, p. 37. 
"Do medo o homem presume estar livre quando não há nada mais de desconhecido. (...) O esclarecimento é a radicalização da angústia mítica. (...) Nada mais pode ficar de fora, porque a simples idéia do 'fora' é a verdadeira fonte da angústia" ${ }^{17}$.

Parece-nos, pois, que o texto de Marcuse, mesmo caracterizando a tecnologia como um sistema, como uma forma de organizar as relações sociais em seu todo, como um instrumento de controle e dominação, não alcança a radicalidade e a tensão histórica do ensaio de Horkheimer e Adorno, que detectam essas mesmas características como manifestação própria da regressão da razão em seu processo de progresso e evolução: “(...) a adaptação ao poder do progresso envolve o progresso do poder, levando sempre de novo àquelas formações recessivas que mostram que não é o malogro do progresso, mas exatamente o progresso bem sucedido que é o culpado de seu próprio oposto"18.

No aprofundamento da perspectiva acima enfatizada, duas temáticas nos parecem centrais nos ensaios: 1 . a mediação do número, do cálculo, da lógica formal, da equação, da padronização na instrumentalidade da razão; 2. a razão que se sedimenta nas máquinas como sua expressão histórica. A primeira temática é mais incisiva no ensaio de Horkheimer e Adorno. Para o esclarecimento, ou seja, para a razão, que é saber, que é técnica, o número tornouse seu organon, a unidade transformou-se em sua divisa, de Parmênides (pré-socrático) a Pierre Lewy (pós-moderno). A ratio só reconhece como ser (dimensão ontológica) e como acontecer (dimensão histórica) aquilo que se deixa compreender pela unidade; tudo o que não se reduz a número, ao uno, passa a ser ilusão, um palavreado sem sentido; ainda mais, é encarado como suspeito. $\mathrm{O}$ procedimento matemático torna-se assim o ritual do pensamento; ele transforma o pensamento em cálculo, em equação, em abstração. Em consonância com o procedimento matemático está a lógica formal, enquanto "a grande escola da unificação",

\footnotetext{
${ }^{17}$ HORKHEIMER e ADORNO, ibidem, p. 29.
}

${ }^{18}$ HORKHEIMER e ADORNO, opus cit., p. 46.

Educ. e Filos., Uberlândia, v. 20, n. 39, p. 71-88, jan./jun. 2006. 
que torna o heterogêneo comparável, equivalente, reduzindo-o a grandezas abstratas; que elimina ambigüidades e imprecisões nas proposições e nas leis; que se manifesta de maneira equivalente e coercitiva, tanto na justiça burguesa quanto na troca mercantil. E sob o domínio nivelador do abstrato, prevalece o universal, o todo na eliminação do indivíduo, do particular ${ }^{19}$.

Para Marcuse, uma nova racionalidade se instaura com a mecanização e a padronização do mundo pela máquina. Esta é um aparato racional que combina máxima eficiência com máxima conveniência, que economiza tempo e energia, que adapta todos os meios a um fim, sustentando a calculabilidade e a segurança do sistema. Aquele que seguir as instruções dessa nova racionalidade poderá ser bem sucedido. Adaptar-se ao aparato é a palavra de ordem. Cada vez mais desaparece o espaço para a autonomia e se manifesta a impotência do pensamento crítico. "Racional - diz ele - é aquele que mais eficientemente aceita e executa o que lhe é determinado, que confia seu destino às grandes empresas e organizações que administram o aparato". A racionalidade tecnológica, que se manifesta de maneira paradigmática no caráter objetivo e impessoal da burocracia, confere aos grupos que a adotam uma espécie de dignidade universal ${ }^{20}$.

A segunda temática, que é um desdobramento da primeira, mostra que a razão se sedimenta nas máquinas como sua expressão histórica. No texto de Horkheimer e Adorno essa questão é tratada de maneira nua e crua. Algumas expressões caracterizam-na bem, como A máquina substitui a razão: "O pensar reifica-se num processo automático e autônomo, emulando a máquina que ele próprio produz para que ela possa finalmente substitui-lo". O esclarecimento renega sua função histórica de "pensar o pensamento" para se fazer igual ao aparato técnico, para que esse se faça razão e, como uma aparelhagem 'matematizada', abstrata, universal, subjugue o que existe, se reproduza indefinidamente e

${ }^{19}$ HORKHEIMER e ADORNO, ibidem., pp. 22-23; $28 ; 37$.

${ }^{20}$ MARCUSE, opus cit., pp. 80-81; 94; 97. 
espalhe pelo mundo a irracionalidade. "Desse modo o esclarecimento regride à mitologia da qual jamais soube escapar"21. A razão enquanto um mero auxiliar da máquina: "(...) a própria razão se tornou um mero adminículo da aparelhagem econômica que a tudo engloba. Ela é usada como instrumento universal servindo para a fabricação de todos os demais instrumentos". Na Idade Média, a razão, o pensar, eram utilizados como instrumento a serviço dos interesses culturais, ideológicos e políticos da Igreja em comunhão com os senhores feudais - philosophia ancilla teologiae; na era das máquinas, a razão, "rigidamente funcionalizada", é utilizada como instrumento de um novo poder, ainda mais forte e universal, o capitalismo transnacional. Com a expulsão do pensamento da razão dominante, com a invasão das máquinas em todos os setores da sociedade, o homem se torna coisa, instrumento, auxiliar da máquina, na fábrica, no escritório e na sala de aula. E com isso, “(...) o horizonte sombrio do mito é aclarado pelo sol da razão calculadora, sob cujos raios gelados amadurece a sementeira da nova barbárie" 22 .

Em Marcuse, essa questão é tratada também de maneira radical na era das máquinas. A tecnologia, como uma das manifestações do pensamento, gera uma "nova racionalidade", a racionalidade tecnológica, e "o poder tecnológico do aparato afeta toda a racionalidade daqueles a quem serve". Portanto, a tecnologia é fruto da razão prática, é uma de suas expressões, que se sedimenta nos aparatos, e atinge a todos que fazem uso desses aparatos, em qualquer setor da sociedade, em qualquer sistema econômico, político, ideológico:

(...) a concepção instrumental da racionalidade tecnológica está se infiltrando por quase todo o reino do pensamento e dá às várias atividades intelectuais um denominador comum". Há uma racionalidade imbricada na tecnologia que

${ }^{21}$ HORKHEIMER e ADORNO, opus cit., pp. 37-39.

${ }^{22}$ HORKHEIMER e ADORNO, opus cit., pp. 42-43.

Educ. e Filos., Uberlândia, v. 20, n. 39, p. 71-88, jan./jun. 2006. 
se infiltra em seus usuários, sejam eles quem forem, estejam onde estiverem. E o comportamento humano se reveste da racionalidade do processo da máquina, que solidifica um conteúdo social definido, como: padrões de comportamento mecânico e padronizado, fetichização da máquina, uma maior eficiência do controle hierárquico sobre os homens, eliminação do desperdício, subordinação do pensamento a padrões externos preestabelecidos, enfraquecimento dos valores críticos. E o indivíduo "mudou sua função; de uma unidade de resistência e autonomia, ele passou a outra de maleabilidade e adaptação. É esta função que associa indivíduos em massas ${ }^{23}$.

Na visão dos autores desses ensaios analisados, quanto mais o processo de tecnologização avança, mais a racionalidade se faz presente e atuante entre os homens em suas diferentes atividades sociais. Haveria alguma possibilidade de mudar o destino das máquinas, de neutralizar seus efeitos regressivos, de usar seu potencial a serviço da emancipação?

Marcuse acredita mais na possibilidade de uma mudança. Para ele, a técnica impede o desenvolvimento individual somente quando está vinculada a um aparato social que perpetua a escassez. E o capitalismo tardio, de seu tempo, era um exemplo histórico disso. Mesmo assim, segundo ele, esse mesmo aparato que oprime libera forças que podem aniquilar a forma histórica particular em que a técnica é utilizada. O que é verdade. $\mathrm{O}$ velho Marx já pensava assim e apontava as contradições entre as forças produtivas revolucionárias e as vagarosas relações sociais de produção como possibilidade de transformações sociais. Contudo, vemos que o progresso do capitalismo nos últimos cinqüenta anos, através da tecnociência, tem destruído continuamente "formas históricas particulares" para criar outras mais condizentes com o seu implacável desenvolvimento. Marcuse fala ainda na "possível

${ }^{23}$ MARCUSE, opus cit., pp. 73-74; 83; 87; 91; 93. 
democratização de funções que a técnica pode promover e que pode facilitar o desenvolvimento humano total em todos os ramos do trabalho e da administração". Para ele, a mecanização e a padronização podem um dia ajudar a mudar o centro de gravidade das necessidades da produção material para a arena da livre realização humana, podem levar a "novas formas de individualização", a "novas formas de desenvolvimento humano" ${ }^{24}$.

Sobre isso Wiggershaus tece o seguinte comentário: "O artigo de Marcuse, Some Social Implications of Modern Technology', permanecia nos sulcos traçados pelos artigos de peso da ZfS dos anos 30 e concluía pelo anarquismo idealista da utopia marcusiana ${ }^{25 "}$. De fato, no final de seu artigo, a manifestação de uma utopia abstrata se faz claramente presente. Diz ele:

O progresso tecnológico possibilitaria diminuir o tempo e a energia gastos na produção das necessidades da vida, além de uma redução gradual da escassez. (...) Quanto menos tempo e energia o homem precisa gastar para manter sua vida e a da sociedade, maior a possibilidade de ele poder 'individualizar' a esfera de sua realização humana ${ }^{26}$.

Isabel Loureiro, em seu artigo "Breves notas sobre a crítica de Herbert Marcuse à Tecnologia" 27, tenta justificar algumas ambigüidades e oscilações nas análises de Marcuse sobre o progresso científico e técnico a partir da distinção feita pelo próprio Marcuse entre técnica e tecnologia, já por nós destacada neste ensaio. Mas, neste texto específico que analisamos - talvez por ser o primeiro artigo dedicado ao tema, em 1941 - Marcuse, mesmo fazendo essa distinção, permanece ambíguo, sobretudo na parte final do texto em que tenta apresentar algumas possibilidades de mudanças.

${ }^{24}$ MARCUSE, opus cit., pp. 101-102.

${ }^{25}$ WIGGERSHAUS, opus cit., p. 327.

${ }^{26}$ MARCUSE, ibidem, $\mathrm{p}, 103$.

${ }^{27}$ LOUREIRO, Breves notas sobre a crítica de Herbert Marcuse à Tecnologia, pp. 19-28.

Educ. e Filos., Uberlândia, v. 20, n. 39, p. 71-88, jan./jun. 2006. 
Horkheimer e Adorno, à semelhança de Marcuse e de Marx, reconhecem que, historicamente, o progresso tem renovado a dominação e, ao mesmo tempo, a perspectiva de seu abrandamento. Reconhecem ainda que o conceito - fruto da razão que se fez ciência - é um instrumento "que serve para distanciar os homens da natureza", mas também que, "enquanto tomada de consciência do próprio pensamento", é um instrumento que permite medir o tamanho assustador da injustiça. E que, portanto, a crítica radical da sociedade continua sendo uma das funções precípuas da razão, não obstante esta ter historicamente mutilado e administrado a reflexão. Dizem eles: "No trajeto da mitologia à logística, o pensamento perdeu o elemento da reflexão sobre si mesmo, e hoje a maquinaria mutila os homens mesmo quando os alimenta" ${ }^{28}$. Há uma intencionalidade de precisão e funcionalidade nos aparatos tecnológicos que fazem com que, mesmo quando utilizados para minorar a dor dos homens, gerem frieza, distância e manipulação.

Horkheimer e Adorno, à semelhança de Marcuse, também concordam que com o imenso desenvolvimento das tecnologias mecânicas, a escassez e a miséria poderiam ser reduzidas e até eliminadas, e os homens poderiam ter mais tempo e energia para se dedicar às "novas formas de individualização". Mas os fatos históricos têm-lhes mostrado continuamente que "na medida em que cresce a capacidade de eliminar duradouramente toda a miséria, cresce também desmesuradamente a miséria enquanto antítese da potência e da impotência" ${ }^{29}$. E que, com a produção mecânica, um tempo mínimo de trabalho seria suficiente para assegurar a subsistência daqueles que ainda eram necessários para o manejo das máquinas; no entanto, a massa imensa da população, que poderia ter mais tempo para "as coisas do espírito", é adestrada, "como um guarda suplementar do sistema" - Marx, teria dito: "como um exército industrial de reserva" - a serviço dos planos

\footnotetext{
${ }^{28}$ HORKHEIMER e ADORNO, opus cit., p. 48
}

${ }^{29}$ HORKHEIMER e ADORNO, opus cit., p. 49 
grandiosos dos donos da sociedade. Os teóricos criticos já vislumbravam nos anos 1940 o desemprego estrutural que assola a sociedade contemporânea com o uso intensivo e ideológico das novas tecnologias ${ }^{30}$.

Os ensaios de Marcuse e de Horkheimer/Adorno, escritos nos anos das revoluções tecnológicas, nos apresentam considerações de como a razão instrumental, sob a forma de máquinas, de aparelhos e de sistemas, se fazia onipresente dominantemente nas indústrias, nos setores financeiros, nos meios de comunicação, nos escritórios, e, através de sua linguagem lógica e operativa, transformava radicalmente os negócios e as pessoas; de como as "virtudes" da eficiência, da organização, da rapidez, da funcionalidade dirigiam a vida na produção e formatavam pessoas aptas ao processo de trabalho; de como a ciência e a tecnologia, aliada ao poder político de estados e de grandes corporações, geravam, ao mesmo tempo, abundância e miséria. Em particular, as análises de Horkheimer e Adorno mostravam que o responsável primeiro pelo aumento da miséria e dos sofrimentos do mundo era o próprio progresso, era a própria razão que se fez técnica e que cada vez mais aumentava seu poder de dominação. Mais ainda, mostravam que, muito embora o desenvolvimento da técnica poderia proporcionar ao homem a trabalhar menos, viver melhor e ter mais tempo para se dedicar à cultura, ao lazer, à vida em sociedade, não era isso o que acontecia.

Nos dias de hoje, pouco mais de sessenta anos após os escritos analisados, o prognóstico radical dos frankfurtianos se revela ainda mais sombrio e preocupante. A aceleração das revoluções tecnológicas e a continuidade da articulação do desenvolvimento tecnocientífico com o capital, agora global, aumentaram assustadoramente a presença e o poder da ratio em nossa sociedade. Aquele mesmo impulso técnico-científico que provocou as profundas transformações na era das máquinas, particularmente a partir dos anos 1970, desencadeou outras revoluções tecnológicas,

\footnotetext{
${ }^{30}$ HORKHEIMER e ADORNO, ibidem, p. 49
} 
com todas as suas conseqüências para os setores sociais e para as pessoas; e no centro dessas novas tecnologias a poderosa microeletrônica.

Vivemos hoje a era das tecnologias digitais, genéticas e cibernéticas; outras estão vindo por aí. E, em contraposição aos anos 1940, as novas tecnologias não atingem apenas os setores de ponta do poder político e econômico, mas estão em todos os lugares e cada vez encontram mais espaço para preencherem. Entraram de vez na sala de aula, no interior de nossas casas; tornaram-se nossos utensílios pessoais, misturaram-se com nossos membros corporais, manipulam nosso genes. Fizeram de nós indivíduos mais rápidos, interplanetários, interconectados. E, ao mesmo tempo, nos deixaram mais inseguros. Moldaram-nos à sua imagem e semelhança; mas exigem de nós entrega e dedicação. Inundaram o mundo de informações; debilitaram a sensibilidade e a reflexão. Aumentaram a miséria e o desemprego; criaram legiões de pessoas e nações "descartáveis". Ameaçam-nos com o perigo de destruição do habitat humano. As máquinas cresceram em poder e racionalidade. Em contrapartida, Horkheimer e Adorno continuam acusando o sentido do desenvolvimento técnico: "A maldição do progresso irrefreável é a irrefreável regressão" ${ }^{31}$.

\section{Referências Bibliográficas:}

ADORNO, T. W. e HORKHEIMER, M. Dialética do Esclarecimento: fragmentos filosóficos. Trad. de Guido Antônio de Almeida. Rio de Janeiro: Jorge Zahar Editor, 1985.

LOUREIRO, I. "Breves notas sobre a crítica de Herbert Marcuse à Tecnologia". In PUCCI, B., LASTÓRIA, L. A. C. N. e COSTA, B. C. G. da. Tecnologia, cultura e formação ... ainda Auschwitz. São Paulo: Cortez Editora, 2003, pp. 19-34.

\footnotetext{
${ }^{31}$ HORKHEIMER e ADORNO, opus cit., p. 46.
} 
MARCUSE, H. "Algumas implicações sociais da tecnologia moderna". In Tecnologia, Guerra e Fascismo: coletânea de artigos de Marcuse editado por Douglas Kellner. Trad. de Maria Cristina Vidal Borba. São Paulo: Editora da UNESP, 1999, pp. 71-104.

WIGGERSHAUS, R. A Escola de Frankfurt: história, desenvolvimento teórico, significação política. Trad. do alemão de Lilyane DerocheGurgel. Trad. do francês de Vera de Azambuja Harvey. Rio de Janeiro: DIFEL, 2002.

Data de Registro 16/11/05

Data de Aceite 03/03/06 